\title{
DO YOU WANT YOUR LEADER TO BE AUTHENTIC? THE EFFECT OF AUTHENTIC LEADERSHIP STYLE ON ORGANIZATIONAL CINISM: A RESEARCH ON TEACHERS
}

DOI: 10.17261/Pressacademia.2020.1261

PAP- V.11-2020(33)-p.168-172

Ezgi Dede ${ }^{1}$, Canan Cetin ${ }^{2}$, Burcak Vatansever Durmaz ${ }^{3}$

${ }^{1}$ Ministry of Education, Kisikli Sehit Huseyin Dalgilic School, Istanbul, Turkey. ezgi.math@gmail.com , ORCID: 0000-0002-3975-0904

${ }^{2}$ Marmara University, Department of Business, Istanbul, Turkey. canancetineylul@gmail.com , ORCID: 0000-0002-3498-3346

${ }^{3}$ Bahcesehir University, Graduate School of Social Sciences, Istanbul, Turkey. burcak.vatansever@gss.bau.edu.tr, ORCID: 0000-0001-8940-0761

\section{To cite this document}

Dede, E., Cetin, C., Durmaz, B. (2020). Do you want your leader to be authentic? the effect of authentic leadership style on organizational cinism: a research on teachers. PressAcademia Procedia (PAP), V.11, p.168-172

Permanent link to this document: http://doi.org/10.17261/Pressacademia.2020.1261

Copyright: Published by PressAcademia and limited licensed re-use rights only.

\section{ABSTRACT}

Purpose- The main purpose of this study is to determine the relationship between teachers' perceptions of authentic leadership and the behavior of organizational cynicism and to determine whether authentic leadership is a predictor of organizational cynicism.

Methodology- The study is a relational screening model and the sample of the study consists of 204 secondary school teachers working in the Anatolian side of Istanbul in the 2019-2020 academic year.

Findings- It has been determined that authentic leadership perceptions and organizational cynicism of teachers are above average. Additionally there is a positive relationship between authentic leader ship and teachers' cynicism behavior.

Conclusion- Structural equation modeling was carried out to determine to what extent teachers' organizational cynicism behaviors predicted the authentic leadership behaviors of school principals. According to the analysis results obtained, authentic leadership perception affects teachers' organizational cynicism behavior by $49 \%$ (standardized regression coefficient).

Keywords: Authentic leadership, organizational cynicism

JEL Codes: M40, M41, M48

\section{LIDERINIZIN OTANTIK OLMASINI ISTER MISINIZ? OTANTIK LIDERLiK TARZININ ÖRGÜTSEL SINIZME ETKISI: ÖĞRETMENLER ÜZERINE BIR ARAŞTIRMA}

\section{ÖZET}

Amaç- Bu çalışmanın temel amacı öğretmenlerin otantik liderlik algıları ile örgütsel sinizm davranışı arasındaki ilişkiyi belirlemek ve otantik liderliğin örgütsel sinizmin bir yordayıcısı olup olmadığını tespit etmektir.

Yöntem- Çalışma ilişkisel tarama modelinde olup araştırmanın örneklemini 2019- 2020 eğitim- öğretim yılında İstanbul’un Anadolu yakası ilçelerinde görev yapan 204 ortaokul öğretmeni oluşturmaktadır.

Bulgular- Öğretmenlerin otantik liderlik algılarının ve örgütsel sinizm davranışlarının ortalamanın üzerinde olduğu tespit edilmiştir. Bunun yanında otantik liderlik ile öğretmenlerin sinizm davranışları arasında pozitif yönde anlamlı bir ilişki söz konu olduğu görülmektedir .

Sonuç- Öğretmenlerin örgütsel sinizm davranışlarının okul müdürlerinin otantik liderlik davranışlarını ne ölçüde yordadığını belirle mek için yapısal eşitlik modellemesi yapılmıştır. Elde edilen analiz sonuçlarına göre otantik liderlik algısı öğretmenlerin örgütsel sinizm davranışlarını \%49 (standardize edilmiş regresyon katsayısı) oranında etkilemektedir.

Anahtar Kelimeler: Otantik liderlik, örgütsel sinizm

JEL Kodları: M40, M41, M48

\section{GíRiş}

Ülkemizde devlet okullarındaki örgün eğitim sisteminde çalışan 907.566 öğretmen bulunmaktadır. Buna karşılık öğrenci sayısı ise 15.088.592' dir (TUIK, 2019). İlgili sayılara göre öğretmen başına 17 öğrenci düşmektedir. Ortaokul seviyesinden itibaren branş derslerinin de devreye girmesiyle birlikte fiilen öğretmen kat kat fazla öğrenci ile ilgilenmektedir. Öğretmen başına düşen öğrenci sayısının bu kadar fazla olduğu bir ortamda öğretmenden istenen verimin alınabilmesi, ancak bu işi öğretmenin gönülden isteye rek yapmasıyla mümkündür. Bunun için öğretmenlerin sinizm olarak ifade kuruma karşı negatif inanç, tutum ve davranışlardan uzak olması gerekmektedir. Bu noktada, okul müdürlerinin liderlik tarzları önem arz etmektedir. Okul müdürlerinin öğretmenleri doğru yönlendirmesi, onlara gerekli bilgilendirmeleri 
zamanında yapması, şeffaf, ahlaki değerlere önem veren bir yönetici olması beklenmektedir. Bu kapsamda öne çıkan liderlik tar zlarından birisi de otantik liderliktir. Otantik lider, ahlaki değerlere göre karar veren, takipçilerine geri bildirimde bulunan, dürüstlük ve şeffaflığı ön planda tutan ve takipçilerinin mutluluğunu önemseyen liderdir (Avolio ve Gardner, 2005; Shamir ve Eilam, 2005; Klenke, 2007).

Bu çalışmada; yöneticilerin otantik liderlik davranışlarının öğretmenlerin sinizm davranışları üzerinde anlamlı bir etkisinin olup olmadığı araştırılacaktır.

\section{LITERATÜR INNCELEMESI}

Otantik liderlik, Luthans ve Avolio (2003)'a göre liderlik daha fazla öz farkındalığa sahip olduğu, içsel bir ahlak anlayışı ile hareket ederek bilginin dengeli dağılımını sağlayan ve takipçilerine ilişkilerde şeffaflığı teşvik ederek onların hem olumlu psikolojik kapa sitelerini artıran hem de olumlu etik iklimi temel alan bir liderlik modelidir (Luthans ve Avolio, 2003). Otantik liderlik dört boyut altında incelenmektedir. Bunlardan ilki öz farkındalıktır. Bu boyut, kendini bilme olarak da ifade edilebilir. Kendini bilen, öz farkındalığı olan kişi diğer kişilerin kendini nasıl gördüğünü ve onları nasıl etkileyeceğini bilir. Kişi, değerleri, inançları, fikirleri ve kendini anlama yeteneğinin yanında kendisinin güçlü ve zayif yönlerinin de farkında olur. İkinci boyut ilişkilerde şeffaflık boyutudur. Bu boyutta kişi sahte bir benlik yerine karşısındakine öz benliğini sunar. Başka bir ifadeyle elindeki bilgiyi açıkça paylaşır, duygu ve düşüncelerini içtenlikle ifade eder. Başkalarının duygularını, düşüncelerini ve fikirlerini ifade etmeleri için fırsatlar sağlayarak ilişkilere güveniklimi geliştirerek yüksek düzeyde bir şeffaflık düzeyini teşvik edecektir. Üçüncü boyut ise bilgiyi dengeli değerlendirme boyutudur. Lider karar vermeden önce ilgili verileri objektif olarak inceler, analiz eder ve kişilerin zit görüşlerini görüşleri söylemeleri için teşvik eder. Dördüncü boyut ise içselleştirilmiş ahlak boyutudur. Bu boyut öz düzenleme becerisinin içselleştirilmiş ve bütünleşmiş biçimidir. Lider örgütsel ve sosyal baskıların aksine ahlaki ve değer standartlarına dayalı eylemlere rehberlik eder, etik ve ahlaki davranışları üst düzeyde yapar ve kararları ve davranışları bu içselleştirilmiş değerlerle tutarlıdır. Otantik liderlerin daha etik bir şekilde davranmaları ve değer yapılarına uygun davranmaları beklenir (Walumbwa ve diğerleri, 2008; Hannah ve diğerler i, 2011).

Örgütsel sinizm "kişinin çalıştığı kurama karşı kuruluşun bütünlükten yoksun olduğu inancı ile başlayıp örgüte duyduğu olumsuz duygu ve bu inançlarla tutarlı olan örgüte yönelik aşağılayıcı ve eleştirel davranış eğilimleri ile devam eden olumsuz bir tutum” olarak tanımlanabilir (Dean vd., 1998, s. 345). Tanımdan da anlaşılacağı üzere örgütsel sinizmin üç boyutu vardır; bilişsel sinizm, duygusal sinizm ve da vranışsal sinizm. Bu boyutlar; örgütler hakkında inanç eksikliği, olumsuz duygular ve eleştirel davranışları kapsamakta dır. Örgütsel sinizmin bilişsel boyutunda, insanların davranışları öngörülemez ve düzensizdir, ayrıca insanlar yalan söyleyebilir ve hile yapabilirler. Örgütsel sinizmin duygusal boyutunda öfke, utanç gibi insanların sadece olumsuz inançları değil, aynı zamanda örgütlere karşı olumsuz duyguları da söz konusudur. Örgütsel sinizmin davranışsal boyutunda, alaycı davranışları olan çalışanlar, organizasyondaki olaylar hakkında güvensiz durumlar olduğu konusunda şüphe duyarlar ve olumsuz şekilde davranabilirler (Dean vd., 1998; Arslan, 2018: 417).

Otantik liderlik ile örgütsel sinizm arasındaki ilişkileri inceleyen çalışmalar incelendiğinde alan yazında çok fazla bir çalışmanın olmadığı görülmektedir. Özellikle eğitim alanında ve öğretmenler üzerinde yapılmış çalışmanın yok denecek kadar az olduğu dikkati çekmektedir. Özdemir ve diğerleri (2018) Ahi Evran Üniversitesindeki 208 idari personel ile oluşturdukları çalışmalarında otantik liderlik ve örgütsel sinizm arasında negatif yönlü anlamlı bir ilişki bulmuşlardır. Tabak ve diğerleri (2013) ise Bir Türk firmasındaki 371 çalışan ile yaptıkları çalışma sonuçlarına göre; otantik liderliğin, örgütsel güven ve örgütsel bağlılık ile pozitif yönde, örgütsel sinizm ile ise negatif yönde anlamlı ilişkileri olduğunu tespit etmişlerdir.

Otantik lider, bilgiyi dengeli değerlendirme, ilişkilerde şeffaflık, içsel ahlak anlayışı ve öz farkındalıktan oluşan dört temel bileşenle birlikte güvenli ve daha sağlıklı çalışma ortamları oluşturur (Wong \& Laschinger, 2013). Avolio ve diğ. (2004), otantik liderlerin bu davranışlar gerçekleştirdiğinde çalışanların işyeri faaliyetlerine aktif katılımını sağlayan daha yüksek kaliteli ilişkiler sağladığını, bunun da daha fazla iş memnuniyeti ve daha yüksek verimlilik ve performans ile sonuçlandığını ileri sürmektedir. İlgili yazın incelendiğinde otantik liderliğin örgüte karşı olumsuz tutum olarak ifade edilen örgütsel sinizmi azaltıcı bir etki yapabileceği düşünülmektedir. Bu doğrultuda aşağıdaki hipotez geliştirilmiştir:

Hipotez 1: Otantik liderlik davranışı, örgütsel sinizm düzeyini negatif ve anlamlı bir yönde etkilemektedir.

\section{YÖNTEM}

Bu araştırmada Milli Eğitime Bakanlığına bağlı ortaokullarda görev yapan öğretmenlerin okul müdürlerine yönelik otantik lider lik algılarının örgütsel sinizm algıları üzerindeki etkisinin ortaya çıkarılması amaçlanmıştır. Çalışma ilişkisel tarama modelinde olup araştırmanınörneklem ini 2019- 2020 eğitim- öğretim yılında İstanbul' un Anadolu yakası ilçelerinde görev yapan 204 ortaokul öğretmeni oluşturmaktadır.

Bu çalışmada iki adet ölçek kullanılmıştır. Ölçeklerin orijinal formlarına uygunluğunu test etmek için AMOS 22 ile doğrulayıcı bir faktör analizi yapılmıştır. Ölçeklerden ilki Walumbwa, Avolio, Gardner, Wensing ve Peterson (2008) tarafından geliştirilen ve Tabak ve diğerleri (2012) tarafından Türkçe'ye uyarlaması yapılan Otantik Liderlik Ölçeğidir. Bu ölçek okul müdürlerinin otantik liderlik davranışlarını belirlemek amacıyla kullanılmıştır. Ölçek, 16 maddeden oluşmakta olup öz farkındalık, ilişkilerde şeffaflık, bilgiyi dengeli değerlendirme, içselleştirilmiş ahlak anlayışı olmak üzere dört alt boyutu içermektedir. Ölçekte yer alan iki madde doğrulayıcı faktör analizi neticesinde fa ktör yük değerleri düşük olduğundan dolayı ölçekten çıkarılmıştır (madde 4 ve madde 9). Ölçeğe ait doğrulayıcı faktör analizi sonucunda elde edilen değerler şu şekildedir: $\mathrm{X} 2=143,960 ; \mathrm{df}=66 ; \mathrm{X} 2 / \mathrm{df}=2,181 ; \mathrm{CFI}=0,969$ RMSEA=0,07 SRMR=0,034. Değerler ölçeğin kabul edilebilir değerler aralığında olduğunu göstermektedir (Hooper vd.. 2008; Hu ve Bentler. 1999). Ölçeğin güvenilirliği .955 olarak bulunmuştur. Öğretmenlerin örgütsel sinizm düzeylerini belirlemek amacıyla ise Brandes, Dharwadkar ve Dean (1999) tarafından geliştirilmiş, Karacaoğlu, K., \& İnce, F. (2012) tarafından Türkçe'ye uyarlanmış 13 maddeden ve üç boyuttan oluşan örgütsel sinizm ölçeği kullanılmıştır. Ölçekte bilişsel, duyuşsal ve davranışsal boyutlara ait maddeler bulunmaktadır. Ölçeğe ait doğrulayıcı faktör analizi sonucunda elde edilen değerler şu şek ildedir: X2= 133,716; $\mathrm{df}=61 ; \mathrm{X} 2 / \mathrm{df}=2,192 ; \mathrm{CFI}=0,96 \mathrm{RMSEA}=0,07$ SRMR= 0,04. Değerler ölçeğin kabul edilebilir değerler aralığında olduğ unu göstermektedir (Hooper vd.. 2008; Hu ve Bentler. 1999). Ölçeğin güvenilirliği ,89 olarak bulunmuştur. 


\section{BULGULAR}

Katılımcıların demografik özelliklerine ait veriler incelendiğinde katılımcıların 67'si erkek (\%32,84), 137'si kadın (\%67,16) öğretmendir. Yaş dağılımına göre katılımcıların 20'si 30 yaşından küçük (\%9,80), 67'si 40 yaşından büyük (\%32,84) ve 117'si 30-40 yaş aralığındadır (\%57,35). Katılımcılardan öğretmenlik mesleğini 1-5 yıl arasında yapanlar 21 kişi $(\% 10,29), 6-10$ yıl arasında yapanlar 46 kişi (\%22,55) ve 11-20 yıl arasında yapanlar 88 kişi $(\% 43,14)$ ve mesleki kıdemi 20 yıldan fazla olanlar ise 49 kişi $(\% 24,02)^{\prime}$ dir. Tablo 1'de otantik liderlik ile örgütsel sinizme yönelik ortalama, standart sapma ve korelasyon değerleri verilmiştir.

Tablo 1: Ortalama, Standart Sapma ve Korelasyon Değerleri

\begin{tabular}{lllll}
\hline Değişkenler & \multicolumn{1}{|}{} & Ss & $\mathbf{1}$ & $\mathbf{2}$ \\
\hline 1.Otantik Liderlik & 3,39 & 0,94 & 1 & $0,40^{* *}$ \\
2.Örgütsel Sinizm & 3,431 & 0,88 & $0,40^{* *}$ & 1 \\
\hline
\end{tabular}

$* * p<0,01$

Tablo 1'den görüldüğü üzere otantik liderlik ortalaması 3,366 ve örgütsel sinizm için 3,431 olarak bulunmuştur. Otantik liderlik ile örgütsel sinizm arasında pozitif yönde anlamlı bir ilişkinin olduğu belirlenmiştir $(r=0,40, p<0,01)$. Yapısal eşitlik modellemesi sonucunda elde edilen standardize edilmiş regresyon katsayıları ( $\beta$ ) Şekil 1'de gösterilmektedir. Buna göre otantik liderlik algısının örgütsel sinizmi anlamlı ölçüde $(\beta=0,49, \quad p<.01)$ yordadığı ortaya çıkmıştır ve bu sonuçlar neticesinde Hipotez 1 reddedilmiştir.

Şekil 1. Kavramsal Modele İlişkin Yapısal Eşitlik Modellemesi Sonuçları

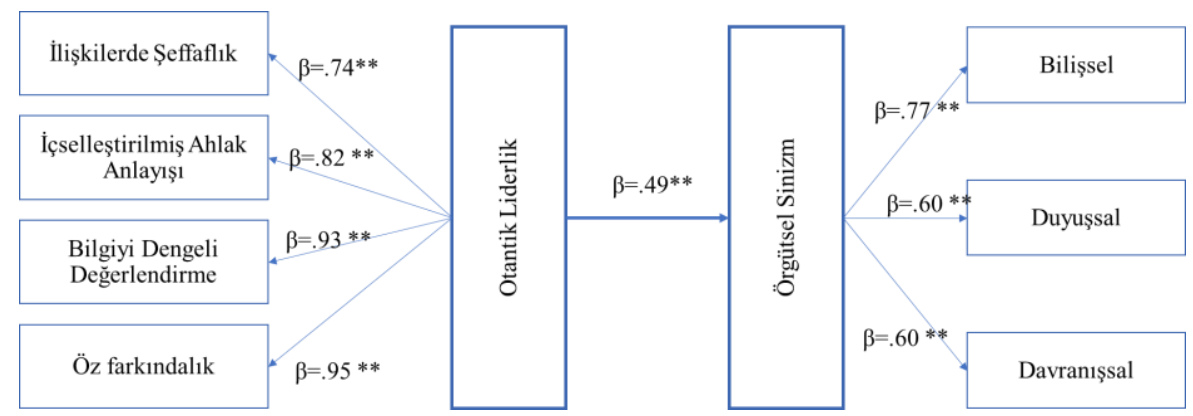

Test edilen modelin yapısal eşitlik modellemesi sonucu elde edilen değerleri aşağıdaki Tablo 2' de gösterilmektedir.

Tablo 2: Model Uyum Indisleri

\begin{tabular}{|c|c|c|c|c|c|c|c|c|c|}
\hline \multirow[t]{2}{*}{ Model } & \multicolumn{6}{|c|}{ Uyum İndisleri } & \multirow[b]{2}{*}{ SRMR } & \multirow[b]{2}{*}{ TLI } & \multirow[b]{2}{*}{$\overline{\text { AGFI }}$} \\
\hline & CMIN & DF & CMIN/DF & GFI & CFI & RMSEA & & & \\
\hline $\begin{array}{l}\text { Hipotetik } \\
\text { Model }\end{array}$ & 19,700 & 12 & 1,642 & 0,974 & 0,99 & 0,056 & 0,031 & 0,984 & 0,939 \\
\hline
\end{tabular}

Yukarıdaki tabloda, modele ait uyum indisi değerlerinin "kabul edilebilir uyum” değerlerine sahip olduğu görülmektedir (Hooper vd. 2008; Hu ve Bentler. 1999). Dolayısıyla modelin kabul edilebilir uyuma sahip olduğu söylenebilir.

\section{SONUÇ VEÖNERILER}

Bu çalışmanın temel amacı öğretmenlerin otantik liderlik algıları ile örgütsel sinizm davranışı arasındaki ilişkiyi belirlemek ve otantik liderliğin örgütsel sinizmin bir yordayıcısı olup olmadığını tespit etmektir. Öğretmenlerin otantik liderlik algılarının ve örgütsel sinizm davranışlarının ortalamanın üzerinde olduğu tespit edilmiştir ki bu sonuç öğretmenlerin sinizm davranışlarının düşük düzeyde bulunduğu bazı çalışmalarda örtüşmemektedir (Atmaca, 2014; Ekinci, 2015; Helvacı ve Çetin, 2012; Kahveci ve Demirtaş, 2015; Akın, 2015; Kalağan ve Güzeller, 2010; Korkut ve Aslan, 2016; Gedik ve Üstüner, 2019). Öğretmenlerin okul müdürlerinin sergilediği otantik liderlik algılarının yüksek olduğunun bulunduğu çalışmalarla ise bu çalışmanın sonucu örtüşmektedir (Keser ve Kocabaş,2014; Nartgün, Nartgün ve Arıcı, 2016; Megeir hi ve diğerleri, 2018). Çalışmanın sonuçlarına göre otantik liderlik ile öğretmenlerin sinizm davranışları arasında pozitif yönde anlamlı bir ilişki söz konu olduğu görülmektedir. Bu sonuçlar literatürde farklı sektörlerde yapılan çalışma sonuçlarına göre farklılık arz etmekted ir (Özdemir ve diğerleri,2018; Erkutlu ve Özdemir, 2018; Yener, 2018). Öğretmenlerin örgütsel sinizm davranışlarının okul müdürlerinin otantik liderlik davranışlarını ne ölçüde yordadığını belirlemek için yapısal eşitlik modellemesi yapılmıştır. Elde edilen analiz sonuçlarına göre otantik liderlik algısı öğretmenlerin örgütsel sinizm davranışlarını \%49 (standardize edilmiş regresyon katsayısı) oranında etkilemektedir. Diğer çalışmalardan farklı bir sonuç olarak göze çarpan bu sonuca göre okul müdürlerinin otantik liderlik davranışları öğretmenlerin sinizm eğilimlerini artırabilmektedir. Diğer çalışmalardan farklı çıkması, araştırmanın kamu okullarındaki öğretmenler üzerinde uygulanmış olması ile açıklanabilir. Otantik liderliğin özellikleri arasında bulunan şeffaflık, değer yargılarına göre karar verme ve doğrudan geri bildirimde bulunma gibi özellikler nedeniyle otantik liderlerin takipçileri tarafından olumsuz karşılanması ve bu sinizme neden olması durumu söz konusu olabilir. Örneğin, bir okul müdürünün bir öğretmene olumsuz bir davranışını dürüstlük, şeffaflık çerçevesinde hiç yumuşatmadan yüzüne karşı 
doğrudan söylemesi öğretmen tarafından kırıcı olarak değerlendirilebilir, öğretmen tarafından müdürü otantik liderlik olarak değerlendirilirken, öğretmenin aynı zamanda sinizm seviyesinin artmasına neden olabilir. Benzer şekilde okul müdürünün öğretmenlerin düşüncelerini açıkça ifade etmesine teşvik etmesi ve bu konuda ısrar etmesi bir otantik lider davranışı iken öğretmenler düşüncelerini açıklamaktan çekinebilir ve okuldan soğuyabilir. Bu durumda da okul müdürünün davranışı otantik liderlik olarak değerlendirilirken öğretmenin sinizm davranışı artmış olacaktır.

Öğretmenler mesleği gereği sürekli öğrencilerle meşgul olan insanlardır. Müdürler tarafından otantik liderlik kapsamında yapılan geri bildirimler ve yönlendirmeler, müdürlerinin kendilerine çocuk gibi (şu konuda hatalısın, şu davranışını düzeltmelisin, gibi) davrandığı şeklinde yorumlanabilmektedir. Bu da sinizmlerini tetiklemektedir. Liderlikte esas olan takipçilerini yönlendirmek ve gelişimlerini sağlamaktır. Araştırma sonucuna göre okul müdürlerinin otantik liderlik çerçevesinde öğretmenler ile olan yönlendirme, geri bildirimi vb. ilişkilerinin doğrudan değil de yumuşatılarak düzenlenmesi gerektiği ortadadır. Araştırma sonuçlarına göre öğretmenlerin örgütsel sinizm düzeylerini azaltmak isteyen okul müdürleri öğretmenlerin mesleklerinde ve iş ortamlarında sıkıntı yaşayanların bu sıkıntılarını etkin dinleme stratejisi ile dinlemeliler. Öğretmenlerin sürekli çocuklarla bir arada olmalarından dolayı duygusal anlamda üst seviyede duygularla iç içe oldukları düşünüldüğünde yaklaşımlarını bir kez daha dikkatlice düşünmelidirler. Bir öğretmen dersini eleştiren, geri bildirim vermeye çalışan bir müdür istemeyebilir. Çünkü branşı, sınıf etkinliği, sınıf yönetimi konularında müdürünün de yeterli bilgi birikimine sahip olmadığını düşünebilir. Okul müdürü gerçekleri söyleyerek, ger bildiğim vererek şeffaflığı sağladığını, bilgiyi dengeli değerlendirdiğini düşünebilir, ancak bu öğretmenlerin gözünden farklı şekilde ( kendi değer yargılarını da ortaya koyabilir, ancak bunun da aynı şekilde görüşünü, değer yargılarını belirtmek istemeyen öğretmenler tarafından algılanması farklı olabilir. Bu durumların toplamı da öğretmenlerin otantik liderlik algılarını artırırken örgütsel sinizm düzeylerini düşürebilir.

Yapılan araştırma Milli eğitim bakanlığına bağı kamu okullarında görev yapan öğretmenlerin otantik liderlik algıları ile örgütsel sinizm düzeyleri arasındaki ilişkiyi incelemeyle sınırlı tutulmuştur. Araştırmacılar özel okullarda görev yapan öğretmenlerin görüşlerini de ortaya çıkarmaya çalışabilir. Otantik liderlik ile örgütsel sinizm algısı örgütsel adalet, örgütsel vatandaşlık davranışı, örgütsel güven değişkenleri ile de ilişkilendirilebilir.

\section{KAYNAKÇA}

A Megeirhi, H., Kilic, H., Avci, T., Afsar, B., \& Abubakar, A. M. (2018). Does team psychological capital moderate the relationship between authentic leadership and negative outcomes: An investigation in the hospitality industry. Economic research-Ekonomska istraživanja, 31(1), 927-945.

Akin, U. (2015). The relationship between organizational cynicism and trust in schools: A research on teachers. Egitim ve Bilim, 40(181).

Arslan, M. (2018). Organizational cynicism and employee performance. Journal of Global Responsibility.

Atmaca, T. (2014). Okul yöneticilerinin kullandıkları güç türleri ile öğretmenlerin yaşadıkları yıldırma, örgütsel bağlılı ve örgütsel sinizm arasındaki ilişki. Gazi Üniversitesi, Eğitim Bilimleri Enstitüsü, Yüksek Lisans Tezi, Ankara.

Avolio, B. J., \& Gardner, W. L. (2005). Authentic leadership development: Getting to the root of positive forms of leadership. The leadership quarterly, 16(3), 315-338.

Avolio, B. J., Gardner, W. L., Walumbwa, F. O., Luthans, F., \& May, D. R. (2004). Unlocking the mask: A look at the process by which authentic leaders impact follower attitudes and behaviors. The leadership quarterly, 15(6), 801-823.

Brandes P, Dharwadkar R, Dean JW (1999) Does organizational cynicism matter? Employee and supervisor perspectives on work outcomes. In Eastern Academy of Management Proceedings, 150-153.

Dean Jr, J. W., Brandes, P., \& Dharwadkar, R. (1998). Organizational cynicism. Academy of Management review, 23(2), $341-352$.

Dean, J.W., Brandes, P. and Dharwadkar, R. (1998), “Organizational cynicism”, Academy of Management Review, Vol. 23 No. 2, pp. $341-352$

Ekinci, S. (2015). Illk ve ortaokul öğretmenlerinin örgütsel özdeşleşme ve örgütsel sinizm düzeylerine ilişkin görüşleri: Bolu ili örneği. Yayınlanmamış Yüksek Lisans tezi, Abant İzzet Baysal Üniversitesi, Eğitim Bilimleri Enstitüsü, Bolu.

Erkutlu, H. V., \& Özdemir, H. Ö. (2018). Otantik liderlik ve sanal kaytarma arasındaki ilişkide örgütsel sinizmin aracı rolü

Gedik, A., \& Üstüner, M. (2019). Öğretmenlerin örgütsel sinizm düzeylerine algıladıkları müdür yönetim tarzının etkisi. Pamuk kale Üniversitesi Sosyal Bilimler Enstitüsü Dergisi, (37), 53-68.

Helvacı, M. A., \& Çetin, A. (2012). İlköğretim okullarında görev yapan öğretmenlerin örgütsel sinizm düzeylerinin belirlenmesi (Uşak ili örneği). Turkish Studies, 7(3), 1475-1497.

Hooper, D., J. Coughlan, and M. R. Mullen, "Structural Equation Modelling: Guidelines for Determining Model Fit", Electronic Journal of Business Research Methods, 2008, 6(1), 53-60.

Hu, L., and P. M. Bentler, "Cutoff Criteria For Fit Indexes in Covariance Structure Analysis: Conventional Criteria Versus Ne w Alternatives", Structural Equation Modeling: A Multidisciplinary Journal, 1999, 6(1), 1-55.

Kahveci, G., \& Demirtaş Z. (2015). İlkokul, ortaokul ve lise öğretmenlerinin örgütsel sinizm algılarının incelenmesi. Elektronik Sosyal Bilimler Dergisi, 14(52). 
Kalağan, G., \& Güzeller, C. O. (2010). Öğr etmenlerin örgütsel sinizm düzeylerinin incelenmesi. Pamukkale Üniversitesi Eğitim Fakültesi Dergisi, 27(27), 83-97.

Karacaoğlu, K., \& Ince, F. (2012). Brandes, Dharwadkar ve Dean'in (1999) örgütsel sinizm ölçeği Türkçe formunun geçerlilik ve güvenilirlik çalışması: Kayseri Organize Sanayi Bölgesi Örneği. Business \& Economics Research Journal, 3(3).

Keser, S., \& Kocabaş, i. (2014). İlköğretim okulu yöneticilerinin otantik liderlik ve psikolojik sermaye özelliklerinin karşılaştırılması. Kuram ve Uygulamada Eğitim Yönetimi, 1(1), 1-22.

Korkut, A., \& Aslan, M. (2016). Organizational Cynicism Levels of Teachers in Secondary Schools in Turkey. Online Submission, 7(2), 91-112.

Luthans, F., \& Avolio, B. J. (2003). Authentic leadership development. Positive organizational scholarship, 241, 258.

Nartgün, Ş, Nartgün, Z. \& Arıcı, U.D. (2016). Okul yöneticilerinin kullandıkları örgütsel güç kaynakları ile otantik liderlik düzeylerine ilişkin öğretmen görüşleri. Çağdaş Yönetim Bilimleri Dergisi, 3(2), 1-26.

Özdemir, H. Ö., Erkutlu, H. V., \& Elden, B. (2018). Otantik Liderlik ve Örgütsel Sinizm Arasındaki Ilişkide Demografik Faktör lerin Düzenleyici Etkisi. International Journal of Social Science, 1(2), 202-210.

Polatcan, M., \& Titrek, O. (2014). The relationship between leadership behaviors of school principals and their organizational cynicism attitudes. Procedia-Social and Behavioral Sciences, 141, 1291-1303.

Tabak, A., Polat, M., Coşar, S., \& Türköz, T. (2012). Otantik liderlik ölçeği: güvenirlik ve geçerlik çalışması. ISGUC The Journal of Industrial Relations and Human Resources, 14(4), 89-106.

Tabak, A., Polat, M., Çoşar, S., \& Türköz, T. (2013). A Research on the Consequences of Authentic Leadership. Bogazici Journa I: Review of Social, Economic \& Administrative Studies, 27(2).

Walumbwa, F. O., Avolio, B. J., Gardner, W. L., Wernsing, T. S., \& Peterson, S. J. (2008). Authentic leadership: Development and validation of a theory-based measure. Journal of management, 34(1), 89-126.

Walumbwa, F. O., Avolio, B. J., Gardner, W. L., Wernsing, T. S., \& Peterson, S. J. (2008). Authentic leadership: Development and validation of a theory-based measure. Journal of management, 34(1), 89-126.

Walumbwa, F. O., Avolio, B. J., Gardner, W. L., Wernsing, T. S., \& Peterson, S. J. (2008). Authentic leadership: Development and validation of a theory-based measure. Journal of management, 34(1), 89-126.

Wong, C. A., \& Laschinger, H. K. (2013). Authentic leadership, performance, and job satisfaction: the mediating role of empowerment. Journal of advanced nursing, 69(4), 947-959.

Yener, S. (2018). Psikolojik rahatlık algısının otantik liderliğin sinizmin üzerindeki etkisinde aracı rolü. Eskişehir Osmang azi Üniversitesi İktisadi ve İdari Bilimler Dergisi, 13(1), 1-14 